\title{
English Past Tense Morphology in Adult Arab EFL learners: Mental Representation Mechanism and Types of Errors
}

\author{
Muneera Muftah (Corresponding Author) \\ Department of English, Faculty of Arts, Thamar University, Yemen \\ Email:muneeramuftah@yahoo.com
}

\begin{abstract}
English past tense morphology is one of the most difficult but yet one of the most important areas in the acquisition of English language by L2 Learners. The objectives of this study were to: (a) determine the acquisition sequence of English regular and irregular past tense forms in adult Arab EFL learners; (b) identify whether English past tense forms are represented by a single mechanism or a dual mechanism, and (c) investigate types of errors that L2 learners produce in their acquisition of English past tense morphology. In total, 77 adult Arab EFL learners participated in an oral production task. The use of the verbal inflectional morphemes in obligatory contexts in each learner's production is examined. The results show that L2 learners acquire the past tense morphology of the regular verbs before they acquire the past tense morphology of the irregular verbs and that there is frequency effect for the irregular verbs, but not for the regular verbs. This indicates that the dual system theory accounts for the mental representations of English past tense forms for the L2 learners in this study. The most frequent error types produced by the Learners are omission, overregularization and overgeneration of be forms.
\end{abstract}

\section{Indexing terms/Keywords}

Second language acquisition; English past tense morphology; adult Arab EFL learners; single system theory; dual system theory

\section{Academic Discipline And Sub-Disciplines}

Linguistics, Morphology

\section{SUBJECT CLASSIFICATION}

Language classification

\section{TYPE (METHOD/APPROACH)}

\author{
Quantitative Research
}

\subsection{INTRODUCTION}

The distinction made between the first language (L1) and second language (L2) acquisition is due to the fact that L2 acquisition appears to be different from the acquisition of L1 especially after the critical period (Towell and Hawkins, 1994: 2). This is because $L 1$ is the language one has developed from birth and the language that is closely intertwined with the development of cognition, i.e. L1 acquisition is an effortless, rapid and uniform process. In contrast, L2 acquisition is a lengthy, highly idiosyncratic and difficult as well as incomplete process. These major distinctions have lead L2 acquisition theorists to claim that $L 2$ acquisition process can take up to seven or more years for a learner to develop proficiency, depending on the age (Alvara, 2003: 157).

In $\mathrm{L} 2$ acquisition, some phenomena that characterized the behaviour of $\mathrm{L} 2$ learners can be observed. Such phenomena are found in all kinds of L2 data, irrespective of the L1/L2 pairings. Towell and Hawkins (1994), for instance, enumerate five main observable phenomena of L2 acquisition including subconscious transfer, staged development, systematicity, variability and incompleteness. Interference of L1 patterns into L2 is of prime significance. It can either enhance or inhibit the acquisition of the L1 (Mitchell and Myles, 2004). If there is a similarity in the structure of the L2 with the L1, the acquisition process will be a lot easier, and if otherwise, it will be more difficult.

One of the intriguing features of L2 acquisition is that some types of grammatical properties appear to be acquired straightforwardly and in a native-like way, while others remain persistently difficult (Liszka, 2001). Rice (1990, in Brackenbury, 2003) has claimed that action words are more difficult to acquire than words from other categories. One common finding from many studies of L2 morphology is that verbal inflectional morphology can be persistently difficult for L2 learners, particularly for adult learners who had begun learning the L2 after childhood. The L2 learners also exhibit variability in their use of inflectional morphology, with tense and agreement morphemes which are frequently omitted in their interlanguage (IL). In other words, the realization of overt morphology is in some sense defective (White, 2010: 9). The 'morphological variability' (White, 2003: 178; White, 2010: 9) with L2 learners often omitting and sometimes incorrectly using obligatory inflectional morphemes or inappropriately substituting one kind of inflection for another has been reported in many studies (see e.g. Geckin and Haznedar, 2008; Hawkins and Casillas, 2008; McCarthy, 2008; Haznedar, 2003; Ionin and Wexler, 2002, Prévost and White, 2000; Lardiere, 2000, 2007, Author, 2011; among others).

The present study focuses on the acquisition of past tense morphology of the English regular and irregular verbs among 77 adult Arab EFL learners. According to Brackenbury (2003), the acquisition of the English past tense is not a simple and easy process. Therefore the present study aims to (i) determine the order of acquisition of English past tense morphology 
in terms of regular and irregular past tense forms, (ii) determine whether the English regular and irregular past tense forms are represented by a single mechanism or a dual mechanism as well as (iii) identify the types of errors that L2 learners produce in their acquisition of English past tense morphology.

\subsection{FRAMEWORK}

A psycholinguistic theoretical framework applicable to the domain of first and second/foreign language acquisition is adapted in his study. Researchers such as Marcus, et al., 1995; Pinker, 1991; Ullman, 1999, in Gor and Chernigocskay, 2003; Bybee, 1995; Stemberger, 1995, in Alegre and Gordon, 1999, among others maintain that underlying mechanism(s) representing the English past tense morphology are at work in the brain. The two competing theoretical frameworks in this area are the 'single system theory', also known as the connectionist model, and the 'dual system theory'.

In fact, English past tense morphology is much debated by researchers over the years in terms of their mental representation(s). Researchers in the single system account (see e.g. Bybee, 1995; Stemberger, 1995, in Alegre and Gordon, 1999) propose that regular and irregular past tense morphology are represented and processed by a single associative memory system. This system is made of neuron-like units which directly map patterns of input (e.g. verb stem) onto patterns of output (e.g. past tense forms) (laviric et al, 2001). Influence of input on output units depends on the strength of the connection between them and it is altered by training. This also shows that learning can take place just on the basis of the input (Rumelhart and McClelland, 1986, in Alegre and Gordon, 1999). The input can be both the regular and irregular verbs, mapped onto output units, which are the past tense forms.

According to Pinker and his colleagues (Marcus, et al., 1995; Pinker, 1991; Pinker and Prince, 1994; Prasada and Pinker, 1993; Ullman, 1999, in Gor and Chernigovskay, 2003), the past tense morphology is represented by a dual system model. This model reflects the different kinds of representations for regular and irregular past tense morphology. Accordingly, irregular past tense forms such as blew, are stored in and retrieved from lexical memory, whereas regular past tense forms, such as walked are produced in real-time by a distinct symbol-manipulation system which applies an -ed suffixation rule to the verb stem, for example walk. There is a blocking mechanism that links these two representations. The retrieval of an irregular will block the application of the -ed rule (blew pre-empts blowed). However, when an irregular is not successfully retrieved, the rule may be applied, resulting in 'overregularization' errors such as blowed, which are the result of over application of the past tense -ed to irregular verb stem (blowed).

\subsection{LINGUISTIC ASSUMPTIONS}

There are there verb tense rules in English, which indicate the present, past and future time. However, this study focuses on the English past tense morphology in order to investigate the acquisition sequence and the mental representation(s) of the $\mathrm{L} 2$ learners in terms of regular and irregular past tense forms.

\subsection{English Past Tense Morphology}

The past tense morphology is considered to be the most widely studied verb tense rule in English (Jacobson, 2002). This is due to its unique property of having two forms of past tense, which are the regular and irregular forms (Jacobson, 2002). The formation of the regular forms is rather simple, that is suffixing-ed to the verb stem, for example, play-played. In other words, the past tense form of the regular verb is completely predictable and determinate. Due to this property, the regulars are said to be easier to learn than the irregulars (westermann 2002, in Bruening, 2002). The regular past tense form in English is marked by suffixation of the inflection -ed to the verb stem:

$$
\begin{aligned}
& \text { V stem + -ed-----------Vpast } \\
& \text { Play + - ed-------------played } \\
& \text { walk + -ed------------walked }
\end{aligned}
$$

The predictability and open-ended productivity of the regular patterns suggests that the regular past tense forms are generated by a mental rule, similar in form to other rules of the grammar, such as the suffixation of -ed to the verb stem. However, although the regulars have the advantage of open-endedness, some are far less pronounceable, such as edited and sixth, than simple English verbs (Pinker, 1998).

On the other hand, the irregulars are defiantly quirky and form their past tense in idiosyncratic ways, such as ring -rang and break-broke (Pinker, 1998). This class is defined as a close-ended class due to its fixed number. Dougherty (2001) claimed that there about 200 irregulars in the English vocabulary and there is no recent addition to the group. In contrast to the rule-governed formation of past tense for the regulars, the formation of the irregular past tense forms is completely unpredictable. The irregulars form their past tense differently, involving a change to the verb stem, either to the vowel (e.g. sing-sang), the final consonant (e.g. make-made), to both vowel and consonant (e.g. keep-kept) or involving suppletion, a complete word replacement of the verb stem (e.g. go-went) (see e.g. Bird et al., 2003). It is suggested that they are memorized as pairs of ordinary lexical items, linked or annotated to capture the grammatical relationship between one word and the other (Pinker, 1998). Only if a verb is based on an irregular verb root will that verb have an irregular past tense form.

Irregular V stem ------------ Vpast
bring -------------------------- brought
go ----------------------------- went
come ---------------------------- came


However, even though the irregulars are less in number and unpredictable compared to the regulars, the ten most commentes and most frequent verbs used are the irregular ones (Westerrnann, 2000 in Bruening, 2002) such as go-went, take-took and break-broke.

\subsection{Arabic Past Tense Morphology}

In Arabic, verbs occur in two main morphological forms, the perfective and the imperfective (Benmamoun, 2000: 24; Aoun et al., 2010: 19). The perfective form is used with the past tense, while the imperfective form is used with the non-past tense and infinitive. These verb forms (the perfective and the imperfective) are not considered tenses because the distinction is not based on time; rather, it is based on the completion of the action or non-completion of the action (Benmamoun, 2000: 28). That is to say, Arabic tenses do not correspond to English ones. The past tense in Arabic, for instance, corresponds to the English simple past, present perfect, and past perfect, as shown in the following example (example adapted from Benmamoun, 2000: 24):

$$
\begin{aligned}
& \text { passed -3sm The-student-nom in the-exam-gen } \\
& \text { 'The student passed the exam.' } \\
& \text { 'The student has passed the exam. or } \\
& \text { 'The student had passed the exam/his exam.' }
\end{aligned}
$$

Verbs in Arabic can agree with subjects in person, number and gender (Ouhalla, 1991). Benmamoun (2000: 19) argues that the main difference between the two verb forms (the perfective and the imperfective) is in the realization of their agreement features. In the present (i.e. imperfective), agreement features are realized by both prefixes and suffixes. In the past tense (i.e. perfective), by contrast, all the agreement morphology is realized by suffixes (Benmamoun, 2000: 19).

\begin{tabular}{|c|c|c|c|c|c|}
\hline \multicolumn{3}{|c|}{$\phi$-features } & \multicolumn{3}{|c|}{ Past Tense Form Agreement suffixes } \\
\hline Person & Number & Gender & Suffix & & uffix \\
\hline $1^{\text {st }}$ & Singular & $f / m$ & $-\mathrm{tu}$ & daras-tu & I studied \\
\hline $2^{\text {nd }}$ & " & $\mathrm{m}$ & -ta & daras-ta & You studied \\
\hline $2^{\text {nd }}$ & " & $f$ & $-\mathrm{ti}$ & daras-ti & You studied \\
\hline $3^{\text {rd }}$ & " & $m$ & $-a$ & daras-a & He studied \\
\hline $3^{\text {rd }}$ & " & $f$ & -at & daras-at & She studied \\
\hline $2^{\text {nd }}$ & Dual & $\mathrm{m} / \mathrm{f}$ & -tumaa & daras-tumaa & You studied \\
\hline $3^{\text {rd }}$ & " & $\mathrm{m}$ & $-\mathrm{aa}$ & daras-aa & They studied \\
\hline $3^{\text {rd }}$ & " & $f$ & -ataa & daras-ataa & They studied \\
\hline $1^{\mathrm{st}}$ & Plural & $f / m$ & -naa & daras-naa & We studied \\
\hline $2^{\text {nd }}$ & " & $\mathrm{m}$ & -tum & daras-tum & You studied \\
\hline $2^{\text {nd }}$ & " & $f$ & -tunna & daras-tunna & You studied \\
\hline $3^{\text {rd }}$ & " & $\mathrm{m}$ & - uu & daras-uu & They studied \\
\hline $3^{\text {rd }}$ & " & $f$ & -na & daras-na & They studied \\
\hline
\end{tabular}
Table 1 (adapted from Benmamoun, 2000: 60-61) shows the different agreement suffixes that can be attached to the perfective form:

Table 1: Perfective/past tense form Agreement Suffixes in Arabic

Thus, it is clear from the table above that the agreement affix is always a suffix when attached to the past tense form of the verb (i.e. perfective). As to the morphological realization of the past tense form, Benmamoun (2000: 27-28) argues that the past tense is not carried by the agreement morphology. He claims that the past tense is an abstract morpheme that does not have any specific phonological realization. The only indicator is suffixal agreement and the suffixal agreement by itself does not realize past tense. Thus, when the verb carries abstract [+past] tense features it carries suffixal agreement; when it does not it carries the prefixal and suffixal agreement associated with the imperfective form.

Hence, in light of the above discussion and in order to understand the acquisition process of English past tense morphology, one has to look at the order of acquisition, the mental representation(s) and the types of errors of English past tense morphology. Therefore, this study intends to address the following research questions:

1. Do adult Arab EFL learners acquire the English past tense morphology in a specific sequence in terms of regular and irregular past tense forms? 
2. Are English regular and irregular past tense morphology represented by the same or different underlying mechanism(s) in the brain that is the single system or the dual system?

3. What types of errors do adult Arab EFL learners make in their acquisition of English regular and irregular past tense forms?

\subsection{METHODOLOGY}

\subsection{Participants}

In total 77 L1 adult Arabic speakers of L2 English participated in this study. They were subdivided into three proficiency levels based on their performance in a standardized proficiency test, the Oxford Placement Test (OPT) (Allan, 1992). The formation of the three groups (advanced (AG), upper-intermediate (UIG) and lower-intermediate (LIG)) was based on a score of $80 \%$ and above for the advanced group, between $61 \%$ and $75 \%$ for the upper-intermediate group and between $41 \%$ and $55 \%$ for the lower-intermediate group. Based on this classification, 20 participants (AG 1- AG 20) were classified as advanced, 25 participants (UIG 1- UIG 25) as upper intermediate and 32 participants (LIG 1- LIG 32) as lower intermediate. The participants were undergraduate university students in Yemen. The learners had had at least seven to eight years of tutored exposure to the English language. The average number of years spent learning English was 7.18 years. However, Arabic language is used extensively in everyday communication in their learning environment.

\subsection{Test Instrument}

The data collection instrument used in this study is an oral production task (ORPT) and that data was subjected to quantitative data analysis with SPSS (Statistical Package for the Social Sciences).

\section{The Oral Production Task (ORPT)}

The oral production task is a picture-based task. The L2 learners are asked by the instructor to take a couple of minutes to look over the pictures first. Then, they are asked to narrate the story as they look through the pictures one by one starting with "One day..." and using the verbs and phrases given under each picture. There are no right or wrong answers in this story telling task. The important thing is that they are allowed to say as much as they can. If the learners do not know a particular word in English, they are allowed to ask the instructor. In case of a verb, the instructor provides the learners with the infinitive form only and the L2 learners need to conjugate the verb as necessary. Their oral production is taped and transcribed.

\subsection{Data Analysis Procedure}

Data was then analyzed using descriptive as well as inferential statistics. The number of instances where the learners produced regular and irregular past tense verb morphemes is counted manually. The mean percentage of correct production for each set of related verb morphemes is calculated. Then, Statistical tests are also run on the learners' production for each of these sets of related items. For the ORPT, the number of instances of the use of the regular and irregular past tense agreement verbal inflectional morphemes in obligatory contexts in each participant's oral production is examined and calculated manually. Obligatory contexts are those contexts in which the morphemes would normally be used in adult English. First, the number of omissions in obligatory contexts in which each morpheme would be omitted by each participant is counted and tabulated. Secondly, the number of tense and agreement errors is counted and tabulated for each participant. The percentages of each item type (omission of inflections; inappropriate use of inflections) for each participant are calculated and compared to find out the production rate as well as the acquisition order of these forms. In addition, the number of other types of structures was calculated to see if the L2 learners resorted to other mechanisms in order to express English past tense morphology specifically. One way ANOVA tests are run on each of these sets comparing mean scores to indicate significant differences in means between the groups of participants. Consequently, post hoc Scheffe tests are conducted by comparing the means between groups to show the significant differences between groups with respect to the regular and irregular past tense inflectional morphemes. Further evidence for the difference in the use of these item types comes from the paired two-sample $t$-tests.

\subsection{RESULTS AND INTERPRETATION}

The use of the verbal inflectional morphemes in obligatory contexts including the regular past tense agreement morpheme $-e d$ as well as the irregular past tense verb forms was examined. First, the number of grammatically inflected items (GI) in obligatory contexts was counted and tabulated. Secondly, the number of omission (OI) in obligatory contexts in which each morpheme was omitted by each learner was also calculated and tabulated. Thirdly, the number of wrongly inflected items (WI) was counted and examined.

\subsection{Grammatically Inflected Items (GI)}

The grammatically inflected items (Gl) include the correct use of English past tense morphology of regular verbs as well as the past tense forms of irregular verbs. The number of obligatory contexts in which English regular and irregular past tense inflectional morphemes were correctly used was presented in Table 2. 
Table2: Mean percentages of correct use (GI) of English past tense morphology in obligatory contexts

\begin{tabular}{|c|c|c|c|c|c|}
\hline \multirow[t]{3}{*}{ Item type } & & \multicolumn{3}{|c|}{ Proficiency Group } & \multirow{3}{*}{ (\%) } \\
\hline & & AG & UIG & LIG & \\
\hline & & $\mathrm{N}=20$ & $\mathrm{~N}=25$ & $\mathrm{~N}=32$ & \\
\hline \multirow[t]{6}{*}{ Gil past tense verbs } & & $179 / 220$ & $74 / 135$ & $42 / 165^{-}$ & $295 / 520$ \\
\hline & & $81.36 \%$ & $54.81 \%$ & $25.45 \%$ & $56.73 \%$ \\
\hline & regular verbs & $165 / 197$ & $55 / 95$ & $34 / 128$ & $254 / 420$ \\
\hline & & $83.76 \%$ & $57.89 \%$ & $26.56 \%$ & $60.48 \%$ \\
\hline & irregular verbs & $14 / 23$ & $19 / 40$ & $8 / 37$ & $41 / 100$ \\
\hline & & $60.87 \%$ & $47.50 \%$ & $21.62 \%$ & $41.00 \%$ \\
\hline
\end{tabular}

$\mathrm{Gl}=$ grammatically inflected items; $A G=$ advanced group; UIG=upper-intermediate group; LIG=lowerintermediate group

The results presented above show that the advanced learners (AG) performed at near native-like level in the GI past tense verbs $(81.36 \%)$. The performance of the upper-intermediate group (UIG) was lower $(54.81 \%)$ for these item types while the lower-intermediate learners' (LIG) scores were the lowest in the task (25.45\%). A comparison of the learners' overall accuracy scores between the regular as well as irregular past tense verbs showed that the learners have performed better on regular verbs (83.76\% for the AG, $57.89 \%$ for the UIG and $26.56 \%$ for the LIG) than on the irregular verb forms $(60.87 \%$ for the AG, $47.50 \%$ for the UIG and $21.62 \%$ for the LIG). These findings indicate that English irregular past tense forms posed more difficulty for the adult Arab EFL learners. A one-way ANOVA revealed a significant difference among proficiency levels with respect to Gl past tense verbs $(F(2,74)=17.757, p=.0001)$. Post-hoc Scheffe tests on these items indicated significant differences $(p<.05)$ in the accuracy scores among the three groups of learners. The low performance of the L2 learners on past tense verb items is attributed to difficulty in acquiring irregular past tense verbs. A one-way ANOVA found a highly significant difference among the learners with respect to irregular verb items $(F(2,74)=14.590, p=$ $.0001)$ as well as regular verb items $(F(2,74)=3.550, p=.031)$. Post-hoc Scheffe tests on irregular verbs showed significant differences $(p<.05)$ between the accuracy scores of the LIG on the one hand and that of the AG and the UIG on the other. Paired two-sample $t$-tests also revealed that the difference in acceptance levels of regular and irregular verb items is highly significant across all groups collectively $(t(76)=3.480, p=.001)$ However, no significant differences $(p>.05)$ were found in the learners' performance on regular verbs which suggested that the L1 Arabic learners have mastered the regular past tense agreement morpheme -ed and have not acquired the irregular past tense verbs.

\subsection{Omission Items (IO)}

Table 3 presents the number and the percentages of the ungrammatical omission (OI) of English regular and irregular past tense verbal inflectional morphemes including the number of omission in obligatory contexts in which each morpheme was omitted.

Table 3: Mean percentages of incorrect use (OI) of English past tense morphology in obligatory contexts

\begin{tabular}{|c|c|c|c|c|c|}
\hline \multirow[t]{3}{*}{ Item type } & & \multicolumn{3}{|c|}{ Proficiency Group } & \multirow{3}{*}{$(\%)$} \\
\hline & & \multirow{2}{*}{$\begin{array}{l}\text { AG } \\
\mathrm{N}=20\end{array}$} & \multirow{2}{*}{$\begin{array}{l}\text { UIG } \\
\mathrm{N}=25\end{array}$} & \multirow{2}{*}{$\begin{array}{l}\text { LIG } \\
\mathrm{N}=32\end{array}$} & \\
\hline & & & & & \\
\hline \multirow[t]{6}{*}{ Öl past tense verbs } & & $34 / 220$ & $46 / 135$ & $86 / 165$ & $166 / 520$ \\
\hline & & $15.45 \%$ & $34.07 \%$ & $52.12 \%$ & $31.92 \%$ \\
\hline & regular verbs & $28 / 197$ & $32 / 95$ & $67 / 128$ & $127 / 420$ \\
\hline & & $14.21 \%$ & $33.68 \%$ & $51.34 \%$ & $30.24 \%$ \\
\hline & irregular verbs & $6 / 23$ & $14 / 40$ & $19 / 37$ & $39 / 100$ \\
\hline & & $26.09 \%$ & $35.00 \%$ & $52.35 \%$ & $39.00 \%$ \\
\hline
\end{tabular}

$\mathrm{OI}=$ omission items; $A \mathrm{G}=$ advanced group; UIG=upper-intermediate group; LIG=lower-intermediate group 
The results show that omission was greater for the irregular past tense forms $(26.09 \%$ for the AG, $35.00 \%$ for the UIG and $52.35 \%$ for the LIG) than for regular past tense forms (14.21\% for the AG, 33.68\% for the UIG and $51.34 \%$ for the LIG) across the three groups of learners with the lower-intermediate group having the highest omission rate for both regular and irregular verb form morphemes. That is to say, the adult Arab EFL learners tended to omit the irregular past tense morphemes more often than that of regular ones. The L2 learners have stabilized at below $80 \%$ in this set of items suggesting failure to acquire verb forms to a native/near native-like level. The learners have wrongly accepted items such as *the celebration begin in the faculty last week as grammatical showing non-native-like competence. A one-way ANOVA found a highly significant difference among the learners with respect to omission of irregular verb morphemes $(F(2,74)=$ 8.166, $p=.000)$ as well as omission of regular verb morphemes $(F(2,74)=4.489, p=.031)$. Post-hoc Scheffe tests showed significant differences $(p<.05)$ between the accuracy scores of the lower-intermediate group and that of the advanced on both sets of items. The learners are indeterminate in their intuition concerning the ungrammatical omission of irregular past tense morphemes indicating that acquisition of irregular forms are problematic for the Arab EFL learners. Some instances of the omission of regular and irregular past tense agreement morphemes are given below:

i. Omission of the past tense agreement morpheme -ed
*While they were playing, one of the boys kick(ed) the ball over a wall (taken from AG 9)

*Both of them explain(ed) to her what happen(ed) when they were playing football (taken from UIG 22)

* the celebration begin(began) in the house last week (taken from LIG 17)

*They come(came) to owner's house and explained the problem (taken from AG 6) past tense agreement morphemes

\subsection{Wrongly Inflected Items (WI)}

The ungrammatical use of English regular and irregular past tense verbal inflectional morphemes includes the number of wrongly inflected items in obligatory contexts. Table 4 shows the oral production data of the past tense verb morphemes wrongly used with inappropriate person, number or tense.

Table 4: Mean percentages of incorrect use (WI) of English past tense morphology in obligatory contexts

\begin{tabular}{|c|c|c|c|c|c|}
\hline \multirow[t]{3}{*}{ Item type } & & \multicolumn{3}{|c|}{ Proficiency Group } & \multirow{3}{*}{ (\%) } \\
\hline & & & UIG & LIG & \\
\hline & & $\mathrm{N}=20$ & $\mathrm{~N}=25$ & $\mathrm{~N}=32$ & \\
\hline \multirow[t]{6}{*}{ Wi past tense verbs } & & $7 / 220$ & $15 / 135$ & $37 / 165$ & $59 / 520$ \\
\hline & & $3.18 \%$ & $11.11 \%$ & $22.42 \%$ & $11.35 \%$ \\
\hline & regular verbs & $4 / 197$ & $8 / 95$ & $27 / 128$ & $39 / 420$ \\
\hline & & $2.06 \%$ & $8.42 \%$ & $21.09 \%$ & $9.29 \%$ \\
\hline & irregular verbs & $3 / 23$ & $7 / 40$ & $10 / 37$ & $20 / 100$ \\
\hline & & $13.04 \%$ & $17.50 \%$ & $27.03 \%$ & $20.00 \%$ \\
\hline
\end{tabular}

$\mathrm{Ol}=$ wrongly inflected items; $A G=a d v a n c e d$ group; UIG=upper-intermediate group; LIG=lowerintermediate group

As presented above, the three groups seemed to make fewer errors in the use of the regular past tense agreement morpheme -ed $(2.06 \%$ for the AG, $8.42 \%$ for the UIG and $21.09 \%$ for the LIG), than the irregular past tense morphemes (13.04\% for the AG, $17.50 \%$ for the UIG and $27.03 \%$ for the LIG). In general, the results show wrong use of the irregular past tense verb forms (20.00\%) was greater than that of the past tense verb forms (9.29\%). Again, the learners' inaccuracy and wrong use of irregular past tense verb forms were higher than that of the regular past tense verb forms. Paired two-sample $t$-tests showed that the difference is marginally significant $(p<.05)$ across all groups of learners collectively. This is actually due to the low performance of the UIG (17.50\%) and the LIG learners $(27.03 \%)$ on irregular past tense forms involving suggesting failure to acquire these items to a native/near native-like level. The learners have wrongly accepted items such as * she draws a picture in school yesterday as grammatical showing non-native-like competence. A one-way ANOVA found a highly significant difference among the learners with respect to wrong use of irregular verb forms $(F(2,74)=9.879, p=.000)$ as well as wrong use of regular verb forms $(F(2,74)=6.662, p=.002)$. Moreover, Post-hoc Scheffe tests showed significant differences $(p<.05)$ among the groups of learners except between that of the AG and the LIG learners. Although, these irregular verb morphemes proved to be problematic for the intermediate learners, improvement was observed with the advanced learners who exhibited better performance. Some of the errors identified in the use of past tense verb inflectional morphemes are given below: 
i. Overregularization

ii. Suffixation of -ing (V+ing)

iii. Suffixation of the non-past third person singular agreement morpheme $-s$

iv. Substitution (past progressive instead of simple past tense)

v. Overgeneration of be forms
* She answered and gived them their ball (taken from AG 11)

*They spending a good time in the party (taken from AG 11)

*Then, the woman invited a lot of children and asks them to celebrate in a birthday party (taken from UIG 15)

*The two boys were happy because they enjoyed the time of the party. In addition they were making a lot of friends (taken from AG 16)

\section{*And the two boys was spent time in the party (taken from LIG 30) \\ *They were playing football, then one of boy was kicked the ball over a wall to the backyard (taken from LIG 32)}

In the first erroneous sentence (i), the L2 learners seemed to have generalized the use of the past tense agreement -ed to all past tense verbs, including irregular verb forms. Again, the incorrect overregularization of the past tense morpheme -ed can be attributed to difficulty acquiring irregular past tense verb forms. The adult Aran EFL learners are actually aware of the functional categories of tense and agreement, however, their morphophonological realizations seemed to be problematic for them due to incomplete learning/acquisition of the irregular past tense forms. In (ii) and (iii), the L2 learners had incorrectly over-applied other suffixations that they had already acquired, such as the -ing and the non-past third person singular agreement morpheme $-s$, to the past tense thematic verbs. The $L 2$ learners also failed to use the correct tense in (iv) and overgenerate be forms as shown in (v). Ten (10) instances showed overgeneration of be forms (three from the upper-intermediate group and seven from the lower-intermediate group). The overgeneration of be forms in the L2 learners' IL can be explained in terms of the influence of the L1 (Arabic Language) where the presence of the verb (be verb forms in this case) is obligatory in the past tense. The production of all other tense errors seemed to show that the L2 learners have not yet mastered the English tense system.

\subsection{DISCUSSION}

Basically, there is a consistent order of acquisition of the English grammatical morphemes across $L 2$ learners independent of their language backgrounds, ages and conditions (naturalistic or classroom) in which the L2 is acquired (Towell and Hawkins, 1994). This order of acquisition has many similarities with the L1 order of acquisition. However, there are also differences. Both the acquisition sequences of grammatical morphemes in L1 and second/foreign language acquisition follow a similar pattern, but the order is different (Michell and Myles, 2004). The similarity suggests that the learners are guided by some set of internal principles, and the difference is due to the difference in these internal principles, in some respects at least.

According to Browns's order of acquisition, in L1 learners, the acquisition of irregular verbs precedes the acquisition of regular verbs (Brown, 1973, in Michell and Myles, 2004). This is in contrast with the order of acquisition in second/foreign language acquisition, where the L2 learners first acquire the regular verbs, and then they acquire the irregular verbs (Dulay and Burt, 1974, in Michell and Myles, 2004).

The analyses of the results reveal striking finding that there is a consistent order of acquisition of the past tense morphology of the English regular and irregular verbs. The significant difference between the means of regular and irregular verbs indicated that Arab EFL learners performance in the regular verbs is better that the irregular verbs. This implicates that all the L2 learners in the present study acquire the past tense morphology of the regular verbs before they acquire the past tense morphology of the irregular verbs. In other words, these learners have acquired the default rule of past tense marking which is the suffixation of -ed before they acquire the idiosyncratic past tense forms of the irregular verbs. This order is consistent with Dulay and Burt's (1974) order of acquisition in second/foreign language acquisition.

The results further indicate that all the participants are better at producing regular past tense forms (high and low frequency) than the irregular past tense forms (high and low frequency) in the oral production task. The mean of correctly produced verb forms for the high frequency regular past tense forms (mean=4.8) is significantly higher than the high frequency irregular past tense forms (mean=5.7). Similarly, the mean of correctly produced verb forms for the low frequency regular past tense forms $($ mean $=1.2)$ is significantly higher than the low frequency irregular past tense forms (mean=2.2). This indicates that the results in this study are in support of the dual system theory which hypothesizes that there should be better production of the regular past tense forms compared to the irregular past tense forms (Van der Ley and Ullman, 2001).

The data also indicates that frequency effect is found for the irregular verbs. The mean of correctly produced instances for the high frequency irregular past tense forms (mean=5.7) is significantly higher than the low frequency irregular verbs (mean=2.2).similarly, the mean of frequency counts for high and low frequency irregular verbs respectively, shows a significant difference $(p<.05)$. These results indicate that the frequency (high and low frequency) of the irregular past tense forms predicts the correct productions of the irregular past tense forms. The overall findings are in support of the dual 
ystem theory, as its explanation can account for both regular and irregular verbs for frequency effects. Thus, in conclusion, the explanations above answer the second research question in this stud that is in adult Arab EFL learners, the English regular and irregular verbs are represented and processed by two underlying mechanisms in the brain which are in support of the dual system theory.

As to the types of errors, the analysis of errors in the study reveal that the highest numbers of errors produced by the L2 learners are omission, overregularization and overgeneration of be forms errors. This is followed by irregularization errors, substitution with other real words, distortions or gross distortions, phonological similarity, incorrect suffixation and lastly substitution with semantically-relate words.

\subsection{CONCLUSION}

In summary, it can be concluded that the adult Arab EFL learners acquire the past tense morphology of regular verbs before they acquire the past tense forms of irregular verbs. This acquisition order of the English regular and irregular verbs is consistent with Dulay and Burt's (1974, in Michell and Myles, 2004) order of acquisition in second/foreign language acquisition. Factors that influence the participants' order of acquisition are cognitive maturity and the frequency of exposure.

The most obvious conclusion to emerge from this study is that the English regular and irregular verbs are represented by two underlying mechanisms in the brain for the Arab EFL learners. This finding conforms to the dual system theory. The regular verbs are represented by a rule-governed mechanism and irregular verbs are represented by an associative memory. Thus, frequency effects are found in the acquisition of past tense morphology for the irregular verbs but not for the regular verbs.

The data show that omission, overregularization and overgeneration of be forms errors continue the highest number of errors in this study, followed by irregularization errors, substitution with other real words, distortions or gross distortions, phonological similarity, incorrect suffixation and lastly substitution with semantically-relate words. The adult L2 learners still have to be taught and be frequently expose to the correct past tense forms of the English regular an irregular verbs.

It is suggested that more studies in this area should be carried out to enhance our understanding of how Arab EFL learners acquire English verbs and their past tense morphology, as it is one of the most difficult areas to be acquired in second/foreign language acquisition, but nonetheless, one of the most important areas to be mastered in the English language.

\section{REFERENCES}

1. Alegre, M. \& Gordon, P. 1999. Frequency effects and the representational status of regular inflections. Journal of Memory and Language, 40, 41-61.

2. Alvara, P. 2003. Comprehensive Collection of Papers on English as a Second Language. Aoun, E. J., Benmamoun, E. and Choueiri, L. 2010. The Syntax of Arabic. Cambridge: Cambridge University Press.

3. Benmamoun, E. 2000. The feature structure of functional categories: a comparative study of Arabic dialects. NewYork/Oxford, UK: Oxford University Press.

4. Bird, H., Lambon Ralph, M. A., Seidenberg, M.S., McClelland, J.L., \& Patterson, K. 2003. Deficits in phonology and past-tense morphology: What's the connection? Journal of Memory and Language, 48, 502-526.

5. Brackenbury, T. \& Fey, Marc, E. 2003. Quick Incidental Verb Learning in 4-year-olds: Identification and Generalization. . Journal of Speech, Language, and Hearing Research, 46, 313-327.

6. Dulay, H. S., and Burt, M. K. 1974. Natural sequences in child second language acquisition. Language Learning, 24, 37-53.

7. Geçkin, V., and Haznedar, B. 2008. The morphology/syntax interface in child L2 acquisition: Evidence from verbal morphology. Current Trends in Child Second Language Acquisition: A Generative Perspective, B. Haznedar ve E. Gavruseva (Eds.), 237-270. Amsterdam: John Benjamins.

8. Gor, K., and Chernigovskaya, T. 2003. Formal Instruction and the Mental Lexicon: The Acquisition of Verbal Morphology. In: Housen, A., Pierrard, M. (eds.). Current Issues in Instructed Second Language Learning. Mouton De Gruyter.

9. Hawkins, R. and Casillas, G. 2008. Explaining frequency of verb morphology in early L2 speech. Lingua, 118, 595612.

10. Haznedar, B. 2003. Missing surface inflection in adult and child L2 acquisition. In Proceedings of the 6th Generative Approaches to Second Language Acquisition Conference (GASLA 2002), J. M. Liceras, H. Zobl, and H. Goodluck (eds.), 140-149. Sommerville, MA: Cascadilla Proceedings Project.

11. Ionin, T. and Wexler, K. 2002. Why is 'is' easier than '-s': acquisition of tense/ agreement morphology by child second language learners of English. Second Language Research 18, 95-136. 
2.Jacobson, P, F., 2002. Elicited production and grammaticalityjudgments of English past tense by early sequential bilingual children with specific language impairment. PhD Thesis, City University of New York. Unpublished dissertation.

13. Lardiere, D. 2007. Ultimate Attainment in Second Language Acquisition: A Case Study. Erlbaum, Mahwah, NJ.

14. Lardiere, D. 2000. Mapping features to forms in second language acquisition. In J. Archibald (Ed.), Second language acquisition and linguistic theory, (pp. 102-129). Oxford: Blackwell Publishers.

15. Lavric A.; Pizzagalli D.; Forstmeier S.; Rippon G. 2001. Mapping dissociations in verb morphology. Trends in Cognitive Sciences. 5(7): 301-308.

16. Liszka, S. 2001. Explaining divergent tense marking in advanced L2 speakers Essex Graduate Student Papers in Language and Linguistics. Department of Language and Linguistics, University of Essex, 3, 59-69.

17. McCarthy, C. 2008. Morphological variability in the comprehension of agreement: An argument for representation over computation. Second Language Research, 24, 459-486.

18. Mitchell, R. and Myles, F. 2004. Second Language Learning theories. $2^{\text {nd }}$ ed. New York: Oxford University press.

19. Ouhalla, J. 1991. Functional categories and parametric variation. London: Routledge.

20. Pinker, S. 1998. Words and rules. Lingua. 106, 219-242.

21.Prévost, P. and L. White. 2000b. Missing Surface Inflection or Impairment in second language acquisition? Evidence from tense and agreement. Second Language Research, 16, 103-133.

22. Towell, R., \& Hawkins, R. 1994, Approaches to Second Language Acquisition, Multilingual Matters, Clevedon.

23. Van der Lely and Ullman, M. 2001. Past tense morphology in specifically language impaired children and normally developing children. Language and Cognitive Processes 16, 177-217

24. White, L. 2010. Second language acquisition at the interfaces. Lingua, 121, 577-590.

25. White, L. 2003. Fossilization in steady state L2 grammars: persistent problems with inflectional morphology. Bilingualism: Language and Cognition, 6, 128-141. 